\title{
Can Tofacitinib Offer Protection against COVID-19 Infection?
}

\author{
Tal Goldberger Abraham Zlotogorski \\ Department of Dermatology, Hadassah Medical Center, Hebrew University of Jerusalem, The Faculty of Medicine, \\ Jerusalem, Israel
}

\section{Dear Editor,}

We would like to share our experience with a 10 -yearold patient with long-standing alopecia areata universalis that was treated with tofacitinib $5 \mathrm{mg}$ BID for 8 months, with excellent clinical response (Fig. 1). Following a large family gathering, attended by the patient, with no proper social distancing measures, the patient's father and additional 25 family members were infected with SARS$\mathrm{CoV}-2$. Therefore, the entire family had entered a 14-day quarantine period. During this time, the patient and his 3 siblings were repeatedly exposed, and in close contact with $\sim 100$ SARS-CoV-2-positive patients, in the same quarantine location, and without proper protection. All of the patients' siblings who were quarantined with him had been diagnosed with symptomatic COVID-19 based on PCR results. Strikingly, the patient had no clinical disease and 2 consecutive PCR tests for SARS-CoV-2 were negative, despite continuing the immunosuppressive treatment without dosage modifications. This surprising finding raises the possibility of a potential protective effect of tofacitinib against SARS-CoV-2 infection and further strengthens the assumption that JAK inhibitors might be used for the prevention or treatment of COVID-19 as suggested by a recent correspondence by Richardson et al. [1] who postulated that the JAK inhibitor baricitinib can reduce SARS-CoV-2's ability to infect cells

\section{karger@karger.com www.karger.com/sad \\ Karger $\frac{V}{\%}$}

\section{(C) 2021 The Author(s)}

Published by S. Karger AG, Basel

bOPEN ACCESS by disrupting AP2-associated protein kinase 1. SARSCoV-2 spike protein's interaction with angiotensin-converting enzyme II was shown to facilitate the activation of metalloprotease 17 which consequently results in angiotensin-converting enzyme II shedding from host cells. This results in increased angiotensin II (Ang II) and hyaluronan (HA) concentrations. Ang II then interacts with its receptor Ang II receptor-1, resulting in JAK-STAT
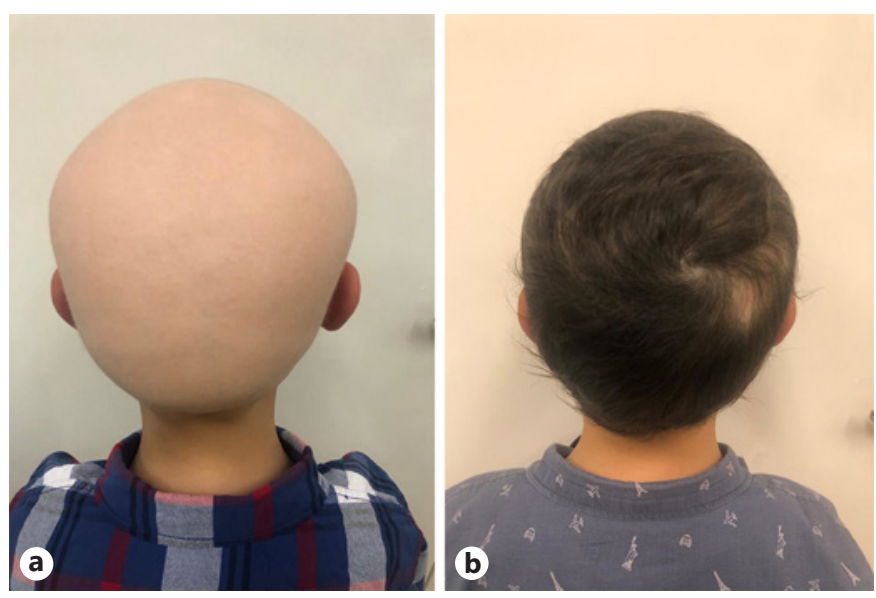

Fig. 1. A 10-year-old patient with alopecia areata universalis before (a) and after (b) 8 months of tofacitinib $5 \mathrm{mg}$ BID treatment.

Abraham Zlotogorski

Department of Dermatology, Hadassah Medical Center, Kiryat Hadassah

Jerusalem 9112001 (Israel)

zlotoa@ hadassah.org.il 
pathway activation, mediating a pro-fibrotic and pro-inflammatory state, as well as chronic tissue injury. The increased HA concentration, on the other hand, may promote the formation of jelly-like fluid in the lungs during the disease, resulting in respiratory distress and severe inflammation. The concentration of HA is also dependent on the induction of HA-synthase- 2 in lung cells by proinflammatory cytokines interleukin-1 and tumor necrosis factor- $\alpha$. Local production of these 2 important cytokines increases due to infiltration of immune cells mediated through the Ang II-JAK-STAT axis [2]. These 2 pathologic processes, and probably several other non-discovered ones, may be counteracted by tofacitinib. The results of emerging clinical trials (NCT04415151, NCT04390061, and NCT04332042) on the use of tofacitinib in COVID-19 patients will shed more light on this important issue.

\section{Statement of Ethics}

The parents of the patient agreed and gave a written consent for the publication of the case and for the use of the clinical image.

\section{Conflict of Interest Statement}

The authors have no conflicts of interest to disclose.

\section{Funding Sources}

No funding was needed for the preparation of this letter.

\section{Author Contributions}

The corresponding author treated the patient, retrieved relevant data for the letter, and critically reviewed the manuscript. The author first drafted the manuscript, and together with the corresponding author conceived the idea of possible cross-protection of JAK inhibitors against SARS-CoV-2 infection and interpreted the clinical data in the context of recent scientific publications.

\section{References}

1 Richardson P, Griffin I, Tucker C, Smith D, Oechsle O, Phelan A, et al. Baricitinib as potential treatment for 2019-nCoV acute respiratory disease. Lancet. 2020;395(10223):e301.
2 Seif F, Aazami H, Khoshmirsafa M, Kamali M, Mohsenzadegan M, Pornour M, et al. JAK inhibition as a new treatment strategy for patients with COVID-19. Int Arch Allergy Immunol. 2020;181(6):467-75. 